\title{
Interações Discursivas: conflitos necessários à construção do conhecimento em comunidades virtuais de aprendizagem
}

\author{
Cláudia Zank - PPGEDU/UFRGS - claudiazank@ gmail.com \\ Lourenço de Oliveira Basso - PPGIE/UFRGS - lourencobasso@ gmail.com \\ Liliana Maria Passerino - PPGIE/UFRGS - liliana@ cinted.ufrgs.br
}

Resumo: A interação tem papel fundamental nos processos de aprendizagem mediados por tecnologias. O objetivo deste artigo é mostrar que interações discursivas podem ser relacionadas com situações de conflito e colaborar para a construção do conhecimento em Comunidades Virtuais de Aprendizagem. Ao apontar a perspectiva do outro e possibilitar a reflexão, o conflito torna-se parte importante do processo de aprendizagem. Neste estudo, após identificar interações ocorridas em ferramentas de comunicação síncrona e assíncrona, realizou-se a análise de conteúdo com base nas categorias: discursos de discordância, esclarecimento e interação didática. Sugere-se, por fim, exemplos de pesquisas que podem contribuir para compreender como se operam os processos de ensino aprendizagem mediados pelo computador e pela Internet.

Palavras-chaves: Interação; conflito, construção do conhecimento; comunidade virtual de aprendizagem.

\section{Discourses Interactions: conflicts required for knowledge construction in learning virtual communities}

Abstract: The interaction has main role in learning processes mediated by technology. This paper intends to show that discursive interactions may be related to conflict situations and even so cooperate for knowledge construction in Learning Virtual Communities. By pointing out the other person perspective and permitting the debate, the conflict becomes an important part of the learning process. This way we identify interactions occurring on synchronous and asynchronous tools and then we analyze its content basing in the follow categories: disagreement discourses, clarification and didactic interaction. Finally, we suggest examples of researches that can help to understand how to operate the processes of teaching and learning mediated by computer and the Internet.

Keywords: interaction; conflict; knowledge construction; learning virtual communities

\section{Introdução}

Desde o aparecimento da World Wide Web muito tem sido discutido sobre as possibilidades comunicativas, colaborativas e cooperativas da aprendizagem mediada por tecnologias (Primo, 2005 e 2007; Barbosa, 2007; Da Costa, 2006). Os avanços teóricos e tecnológicos têm mostrado que a interação, mesmo que por vezes conflituosa, passa a ser fundamental nos processos de aprendizagem (Primo, 2003; Passerino, 2005). E o conflito, ao apontar a perspectiva do outro e possibilitar a reflexão, passa a ser valorizado como parte desse processo.

Interpretações divergentes e conflituosas podem ser expressas pelos conteúdos semânticos dos discursos, segundo Tomasello (2003). No caso das crianças, elas se envolvem diariamente em três tipos de discursos conflituosos: resolver opiniões 
discrepantes; tentar entender e reformular as partes de sua expressão lingüística que os outros não conseguem entender; e tentar entender e coordenar sua própria perspectiva e a do outro que está comentando essa perspectiva. Para Tomasello, estas interações discursivas desempenham um papel importante no desenvolvimento de representações cognitivas dialógicas e auto-reflexivas na primeira infância.

No entanto, tais interações não acontecem apenas na infância, nem tampouco se manifestam apenas na forma oral. Esses discursos podem claramente tomar a forma de conflitos e fazer parte das interações que ocorrem por meio da comunicação escrita nas Comunidades Virtuais de Aprendizagem $\left(\mathrm{CVA}^{1}\right)$ e colaborar para a construção coletiva do conhecimento.

O presente artigo objetiva analisar a relação entre as interações discursivas e o conflito, mostrando a relevância dos discursos conflituosos para a construção do conhecimento nas CVA. Para tal, a seguir será apresentado o papel da interação na construção do conhecimento dentro da perspectiva sócio-histórica, e seguidamente serão abordadas as interações discursivas. Finalmente, no item 4 alguns exemplos de interações discursivas conflituosas e sua relação com a aprendizagem são analisadas com desdobramentos de potenciais pesquisadas elencadas nas considerações finais.

\section{A interação sob uma concepção sócio-histórica}

A teoria sócio-histórica propostas por Vygotsky aborda o desenvolvimento das capacidades psíquicas superiores, também chamadas de processos psicológicos superiores (PPS), as quais se referem aos mecanismos psicológicos mais sofisticados e complexos que diferenciam o ser humano dos demais animais. Os PPS se desenvolvem no contexto social e englobam o controle consciente do comportamento (ação intencional), voluntário e mediatizado pelo uso de instrumentos (signos) (Vygotsky, 1994). No desenvolvimento das capacidades psíquicas superiores, Vygotsky destacou o papel fundamental dos instrumentos de mediação, que constituem um elo intermediário entre o estímulo e a resposta, funcionando como um estímulo de segunda ordem, o qual reestrutura a relação destes dois elementos. Por meio desses instrumentos, o indivíduo pode modificar o ambiente (chamados de instrumentos físicos ou simplesmente instrumentos) ou modificar a si mesmo (denominados instrumentos simbólicos ou signos). Nesse sentido, os signos são estímulos artificiais, ou autogerados, que possuem a característica importante de ação reversa (age sobre o indivíduo e não sobre o ambiente) (Vygotsky, 1994, p. 53), sendo orientados internamente. Já o instrumento é orientado externamente e leva a mudanças nos objetos, constituindo um meio pelo qual a atividade humana externa é dirigida para o controle e domínio da natureza (1994, p. 72).

Para Vygotsky, o controle da natureza e o controle do comportamento estão mutuamente ligados [...]. De um lado, o uso de instrumentos amplia de forma ilimitada a gama de atividades em cujo interior as novas funções psicológicas podem operar, e, por outro lado, o uso de meios artificiais - a transição para a atividade mediada - muda, fundamentalmente, todas as operações psicológicas (1994, p. 73). Desse modo, a mediação simbólica, ao incluir o uso de ferramentas e de signos dentro de um contexto social, possibilita o desenvolvimento dos PPS num processo que passa do social (inter) para o individual (intra) pela internalização ${ }^{2}$ (Passerino e Santarosa, 2000). Nesse sentido, a ação do outro sobre o sujeito que aprende é essencial, pois colabora para o desenvolvimento da Zona de Desenvolvimento Proximal (ZDP).

Segundo Vygotsky, existem dois níveis de desenvolvimento do sujeito: a Zona de Desenvolvimento Real (ZDR), ou seja, tudo aquilo que o sujeito realmente conhece e domina, e a ZDP, uma zona de desenvolvimento que depende do contexto social no 
qual o sujeito está imerso, definida como o potencial que o sujeito pode vir a desenvolver (Vygotsky, 1994, p. 111). Nas palavras de Vygotsky, ZPD é "a distância entre o nível de desenvolvimento real, que se costuma determinar através da solução independente de problemas, e o nível de desenvolvimento potencial, determinado através da solução de problemas sob a orientação de um adulto ou em colaboração com companheiros mais capazes" (1994, p. 112).

O contexto social e a interação permitem ampliar a ZDP, o que constitui um processo de Aprendizagem (Passerino e Santarosa, 2000). Para Vygotsky, a interação social representa um elemento necessário ao processo de aprendizagem e de desenvolvimento do indivíduo, pois "o aprendizado humano pressupõe uma natureza social específica e um processo através do qual as crianças penetram na vida intelectual daquelas que a cercam" (Vygotsky, 1994, p. 115). Assim, na teoria sócio-histórica, a aprendizagem é relacionada não só com as capacidades cognitivas de cada indivíduo, mas também com o meio sócio-cultural em que ele vive.

Esse artigo, portanto, parte do pressuposto de que é a interação entre o sujeito e os integrantes do grupo do qual ele pertence que provoca avanços em direção à construção do conhecimento, uma vez que ela possibilita uma aprendizagem no qual os participantes atuam como mediadores e que acontece por meio da colaboração, da cooperação e do intercâmbio de pontos de vista diferentes (Zank et al., 2008).

A linguagem enquanto intenção comunicativa tem, portanto, papel fundamental na aprendizagem. Parte disso se dá devido às interações discursivas (Tomasello, 2003), ou seja, não só quando há exposição dos diferentes pontos de vista dos sujeitos envolvidos no processo discursivo, mas também quando da reformulação de expressões lingüísticas que os outros não conseguem entender, e da tentativa de entender e coordenar sua própria perspectiva e a do outro que está comentando essa perspectiva. Sobre essas interações discursivas tratará a próxima seção.

\section{Interações Discursivas}

Tomasello (2003) defende a idéia de que os processos sociais e culturais comuns a todas as culturas são parte integrante das vias ontogênicas ${ }^{3}$ de habilidades cognitivas humanas fundamentais, principalmente aquelas únicas da espécie. Para o autor, o uso de símbolos lingüísticos em interações discursivas, nas quais diferentes perspectivas são contrastadas e compartilhadas, colabora para que a criança construa representações cognitivas flexíveis e multiperspectivadas, que dariam à cognição humana um poder único.

Barroso (2007) diz que a percepção de que existem diferentes pontos de vista surge desde o momento da aquisição da linguagem. Ao adquirir a linguagem, a criança está, ao mesmo tempo, incorporando formas produtivas para categorizar e interpretar o mundo, adotando pontos de vista diferentes sobre uma mesma situação, e partilhando, conjuntamente com seu co-específico, intenções comunicativas, na medida em que ambos se constituem como agentes intencionais e mentais.

Nesse contexto, os processos discursivos e de comunicação lingüística são totalmente constitutivos do desenvolvimento cognitivo humano e apresentam três diferentes dimensões: (a) transmissão cultural do conhecimento; (b) função estruturante da linguagem; e (c) discurso e perspectiva conceitual.

Quanto à transmissão cultural do conhecimento às crianças, Tomasello (2003) pontua que ela é necessária porque o conhecimento que se pode obter pela simples observação do mundo é muito pequeno. Com relação à função estruturante da linguagem, o autor afirma que, por meio de interações discursivas, as crianças operam com um conjunto de categorias, relações e perspectivas que tem propriedades únicas, 
uma vez que colaboram para a flexibilidade do pensamento, lhes permitindo criar novas categorias e analogias.

A última dimensão citada por Tomasello, discurso e perspectiva conceitual, refere-se ao fato de que a interação lingüística induz as crianças a adotarem diferentes, múltiplas e conflituosas perspectivas conceituais sobre os fenômenos, uma vez que os discursos podem expressar interpretações divergentes e conflituosas. Nesse contexto de perspectivas conceituais múltiplas e conflituosas, os discursos, segundo Tomasello, são de três tipos: discordância, esclarecimento e interação didática.

$\mathrm{O}$ discurso de discordância ocorre quando as pessoas expressam diferentes conhecimentos e perspectivas ao conversarem sobre um determinado assunto. Nesse tipo de discurso estão incluídos os desacordos, os mal-entendidos e as divergências de opinião (duas opiniões conflitantes sobre o mesmo tema e a criança tem que encontrar uma maneira de conciliar estas opiniões) (2003, p. 238).

O segundo discurso, de esclarecimento, pode ser de dois tipos: o primeiro ocorre quando o ouvinte não entende o que a criança diz e pede um esclarecimento. $O$ segundo tipo acontece quando o parceiro da interação pressupõe algo a partir de um entendimento que fez que, na verdade, difere do que o outro quis dizer (2003, p. 239).

Por fim, há o metadiscurso, no qual a criança expressa uma opinião sobre uma situação e outra pessoa expressa uma opinião sobre aquela opinião, sendo a opinião desta pessoa, muitas vezes, uma crítica. Ao compreender esse tipo de discurso, a criança é levada a examinar seu próprio pensamento a partir da perspectiva do outro.

Segundo Tomasello, as crianças se envolvem diariamente nesses três tipos de discursos em que é preciso adotar a perspectiva de outra pessoa, sendo essa, muitas vezes, divergente. Nesse contexto, as crianças têm de tentar resolver opiniões discrepantes, tentar identificar as partes de sua expressão lingüística que os outros não conseguem entender e reformulá-las, e tentar entender, e às vezes coordenar, sua própria perspectiva e a do outro que está comentando essa perspectiva.

Os discursos de discordância, de esclarecimento e de interações didáticas, em combinação com as outras duas dimensões do processo de desenvolvimento cognitivo inicial, a transmissão cultural do conhecimento e a função estruturante da linguagem, desempenham um papel fundamental no desenvolvimento de representações cognitivas dialógicas e auto-reflexivas na primeira infância (Tomasello, 2003). Para o autor, as interações discursivas possibilitam que as crianças, gradualmente, ganhem experiência com o jogo do inter-relacionamento entre suas próprias mentes e a dos outros. Ao interagirem lingüisticamente com os outros, as crianças entram em contato com uma série de crenças e pontos de vista conflituosos sobre as coisas - este processo constitui, provavelmente, um ingrediente essencial para que as crianças possam enxergar as outras pessoas como seres com mentes semelhantes, mas simultaneamente, diferente delas (Brants, 2008).

Este trabalho pressupõe, então, que as interações discursivas, por expressarem naturalmente divergências de opiniões e conhecimentos, são conflituosas, porém construtivas, uma vez que, segundo Primo (2007, p. 230), os pontos de vista contraditórios não são obstáculos, "mas a própria condição para que os processos de desenvolvimento intelectual e comunicação se movam”. Primo destaca ainda que "o conflito é próprio do ser humano e que comunicação não é sinônimo de transmissão inquestionável nem de intercâmbio consensual (...) interagir é estar em conflito" (2007, p. 198). Para Primo e Moscovici, o conflito pode ser mais produtivo a um grupo do que o consenso ou a concordância, pois esses podem contribuir para a estagnação e não permitir que surjam soluções mais complexas e mais adaptadas ao contexto em questão, uma vez que não acontece a discussão de diferentes perspectivas (2007, p. 210; 1998, p. 
6).Assim, a interação se mostra discursiva e conflituosa, mas também um processo de mediação que colabora para o desenvolvimento da ZPD e, conseqüentemente, da aprendizagem (Vygotsky, 1994).

\section{Interação discursiva, conflito e construção do conhecimento em CVA}

Para atender ao objetivo do presente artigo, que é analisar interações ocorridas em CVA, buscou-se dentro de duas comunidades virtuais (Orkut e Teleduc) analisar as interações discursivas de usuários em ferramentas de comunicação síncrona (chat) e assíncronas (e-mail e fórum). Para tal buscou-se identificar em recortes de diálogos a ocorrência da dimensão do discurso e perspectiva conceitual, proposta por Tomasello (2003) pelos sujeitos participantes. Uma síntese das análises realizadas, e selecionadas para este trabalho, é apresentada a seguir.

Como exemplo ${ }^{4}$ de interação discursiva de discordância segue um trecho de discussão em fórum ${ }^{5}$, no qual os interagentes possuem conhecimentos diferentes a respeito de uma determinada temática, mas que, a partir da reflexão a respeito do que o outro diz, o sujeito passa por um processo de construção mediada do conhecimento:

\begin{tabular}{|c|c|}
\hline (1) & $\begin{array}{l}\text { IVA :Vygotsky NUNCA usou o termo "ideologia". Pessoal, vejam só que } \\
\text { curiosidade interessante: já notaram que Vygotsky nunca mencionou a } \\
\text { palavra "ideologia"? [...] E, tratando-se de um teórico marxista, isso é no } \\
\text { mínimo curioso! [...] }\end{array}$ \\
\hline (2) & $\begin{array}{l}\text { SEL - Usou o termo sim. Não como Marx mas usou. Sinto discordar mas o } \\
\text { termo ideologia aparece na tradução brasileira do "Manuscrito de 1929", } \\
\text { publicado antes em inglês como "Concrete Human Psychology". Não se } \\
\text { trata de um uso tecnicamente similar àquele de Marx para o termo - mas } \\
\text { há uma menção a ele sim. [...] }\end{array}$ \\
\hline (3) & $\begin{array}{l}\text { SEL - Vigotski e o conceito de ideologia. Gostaria de sugerir que a } \\
\text { discussão migrasse do tema "Vigotski NUNCA utilizou o termo 'ideologia"" } \\
\text { para "As contribuições de Vigotski à discussão sobre o conceito de } \\
\text { ideologia". Vejo que o tema, pelo que foi levandado pelos colegas, é } \\
\text { importante. Mas é errôneo dizer que Vigotski nunca usou o termo } \\
\text { "ideologia", pelo que expus há pouco. [...] }\end{array}$ \\
\hline (4) & $\begin{array}{l}\text { IVA - [...] Sei que saí um pouco do tema (o fato dele não ter nunca usado } \\
\text { o termo) até porque mudei a perspectiva de ideologia (da condição de } \\
\text { "termo" para "conceito") e de comparar suas idéias com as de seu } \\
\text { conterrâneo/contemporâneo... mas o conceito de ideologia não parece ser } \\
\text { tão caro para Vygotsky quanto o é para Bakhtin. }\end{array}$ \\
\hline
\end{tabular}

Em (2) aparece a primeira interação de discordância quando SEL se opõe à fala de IVA (1), situação esta que se reafirma em 3. A partir disso, o sujeito IVA muda seu ponto de vista: não só aceita que Vygotsky tenha usado a palavra "ideologia", como passa a discutir o conceito e a fazer outras relações, o que não teria sido possível sem a discordância do colega.

A mesma situação é presente em ferramentas síncronas ${ }^{6}$, como mostrado a seguir num trecho de interação desenvolvida na ferramenta Bate-Papo ${ }^{7}$, no qual ocorre um Discurso de Esclarecimento, ou seja, um primeiro sujeito não entende o que o outro diz e pede um esclarecimento. 
(1) (17:18:53) AID fala para Todos: Peraí...um enunciado pode ser composto por muitas frases ou muitas orações...O Conjunto de orações (e frases) é o período e o conjunto de períodos é que seria o discurso???

(2) (17:21:18) AMO fala para AID: não entendi o que queres dizer com "período"?

(17:24:57) AID fala para AMO: Período é um conjunto de frases/orações. Por (3) exemplo: um parágrafo... uma idéia falada ou escrita...Por isso que pensei em período = enunciado. Ai será que pirei de vez? Hahahaha

(4) (17:26:57) AID fala para Todos: Não, eu que estou fazendo essa relação, $\mathrm{Na}$ verdade, ele nem fala em período. Mas a NAI q fez Licenciatura em Letras $q$ poderia falar melhor sobre isso...

(5) (17:27:33) AMO fala para Todos: acho que está certa a respeito do período... comecei a lembrar das aulas de português...rsrsr... mas acho que a definição de período e enunciado são diferentes... o enunciado não é uma unidade da língua (gramatical), mas uma unidade da comunicação entre sujeitos falantes e ouvintes

Neste trecho, AID faz uma afirmação sobre o conceito de período (1), que por sua vez não é compreendida por AMO que pede um esclarecimento (2) que AID atende (3).

É interessante observar que o esclarecimento feito pelo sujeito AID fez com quem ele mesmo continuasse a refletir a respeito (4) num processo de fala interna socializada (Vygotsky, 2007). Esta ação de reflexão compartilhada provoca uma resposta de AMO contextualizando a temática abordada e fazendo relações (5).

Um outro ponto interessante em uma CVA é que quando as discussões se dão de forma aberta, outras pessoas podem tomar parte da interação discursiva e, conseqüentemente, construir seus conhecimentos, o que caracteriza as afirmações de Primo (2007) e Moscovici (1998) de que o conflito pode ser produtivo. No caso dessa interação síncrona, outros sujeitos se interessam pelo assunto e se juntam à discussão, mostrando reflexão a respeito da temática:

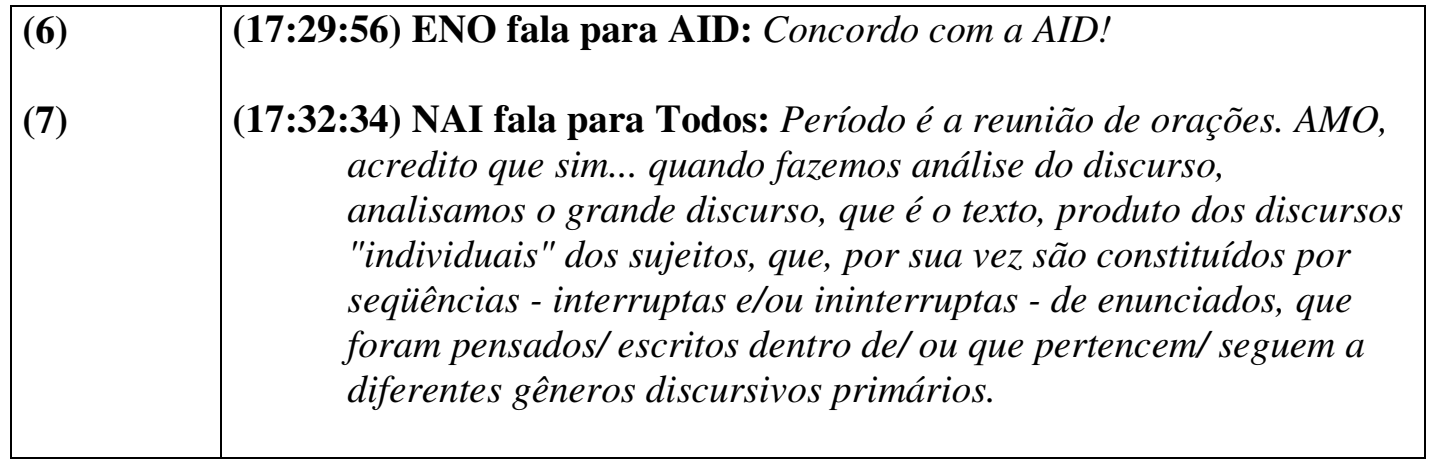


Existe ainda mais uma situação conflituosa proposta por Tomasello (2003), o metadiscurso, no qual o sujeito expressa uma opinião sobre uma situação e outra pessoa expressa uma opinião sobre aquela opinião. Nesse caso, o sujeito é levado a examinar seu próprio pensamento a partir da perspectiva do outro. $\mathrm{O}$ metadiscurso aparece nos trechos abaixo, retirados de interações na ferramenta correio de eletrônico:

\begin{tabular}{|c|c|}
\hline (1) & $\begin{array}{l}\text { Trecho do e-mail de LIL: } \\
\text { Li a conversa de vcs. Acho que podemos delimitar mais, sim. } \\
\text { Dialogismo e escrita coletiva [...] tem a ver com polifonia (sinônimo de } \\
\text { dialogismo), que também está ligada à pluri e multivocidade, e } \\
\text { responsividade. }\end{array}$ \\
\hline (2) & $\begin{array}{l}\text { Trecho do e-mail de ALC: } \\
\text { Acho que precisamos chegar num consenso sobre o entendimento } \\
\text { do trabalho..[...] Escrevi no meu Memorial de Conceitos sobre } \\
\text { multiplicidade e pluralidade de voze e olha o comentário que o AVE fez: } \\
\text { "Esses conceitos me parecem ter mais a ver com a questão da } \\
\text { "polifonia", um nome específico do dialogismo na questão literária, } \\
\text { segundo vimos com BRAIT em nosso mais recente encontro." } \\
\text { Daí o que eu pensei foi o seguinte: como podemos analisar } \\
\text { multiplicidade, pluralidade e polifonia no Bate Bapo se são questões mais } \\
\text { ligadas à auestão a literária? } \\
\text { Por isso que descartei, mas se eu entendi errado, podemos rever esse } \\
\text { posicionamento de incluir esses itens. }\end{array}$ \\
\hline (3) & $\begin{array}{l}\text { Trecho do e-mail de LIL: } \\
\text { ALC... exatamente,.. concordo contigo. dialogismo é a mesma coisa } \\
\text { que polifonia, só que a polifonia se dá na esfera literária; multiplicidade e } \\
\text { pluralidade de vozes são as formas de manifestação da polifonia. } \\
\text { [...] Mas.... existe multiplicidade e pluralismo no dialogismo } \\
\text { (criação não literária), já que apenas não se tem personagens... o resto da } \\
\text { sistemática permanece igual... }\end{array}$ \\
\hline (4) & $\begin{array}{l}\text { lo e-mail de ALC: } \\
\text { ue teu pensamento está supercorreto!! }\end{array}$ \\
\hline
\end{tabular}

Neste exemplo temos a expressão de uma opinião apresentada por LIL (1), a qual é seguida por uma resposta de ALC (2), com opinião contrária à LIL (interação discursiva conflituosa) e que expressa as razões de sua opinião, mas aceita rever seu posicionamento. Então LIL, em nova mensagem (3), mostra argumentação para sua opinião que ao ser aceita por ALC provoca um exame da sua opinião a respeito do tema e a perspectiva do outro (4).

Os exemplos acima foram analisados a fim de mostrar a relação entre interações discursivas e conflito e a importância dessas interações na construção do conhecimento em CVA. Essa análise partiu de um embasamento teórico fundamentado em Vygotsky (1994) e Tomasello (2003) e será retomada na próxima seção.

\section{Possíveis desdobramentos futuros}

Este trabalho procurou mostrar que as interações discursivas, conforme proposto por Tomasello (2003), podem ser relacionadas com as situações de conflito e que 
colaboram para a construção do conhecimento em Comunidades Virtuais de Aprendizagem. À identificação das interações discursiva, seguiu um processo de análise de conteúdo com base nas categorias propostas por Tomasello.

A busca por exemplos de interações discursivas em CVA que ocasionassem a aprendizagem trouxe uma série de questões que se colocam como inspiradoras de futuras pesquisas. Os desdobramentos percebidos são pesquisas, entre outras, sobre mapeamento de ferramentas de comunicação que mais favoreçam as interações discursivas a partir de critérios de usabilidade e de design baseadas na interação como função primordial de tais ferramentas. Também se considera importante o estudo de formas de solução de conflitos nas CVA a partir da coordenação de discursos e ações evidenciadas pelos mesmos. Um outro ponto que consideramos importante é a busca de marcadores conversacionais que dêem indícios de processos discursivos de conflitos em CVA (Passerino et. al. $\left.{ }^{8}, 2008\right)$. Estes e outros são exemplos de pesquisas que podem contribuir para uma maior compreensão de como se operam os processos de aprendizagem mediados pelo computador e pela Internet.

\section{Notas de Texto}

As comunidades virtuais de aprendizagem são comunidades virtuais criadas a partir de objetivos definidos, principalmente o de desenvolver habilidades e competências e de formação geral ou profissional em determinado grupo, agrupando e oferecendo dispositivos de informação e comunicação para seus integrantes travarem relações com o objetivo comum de aprender (Sartori e Roesler, 2003).

${ }^{2}$ A utilização de marcas externas (signos externos) vai aos poucos se transformando em processos internos de mediação. Processo de Representação mental - operar

mentalmente sobre o mundo - fazer relações, planejar, comparar, lembrar - liberdade ao homem da necessidade da interação concreta com os objetos de seu pensamento.

${ }^{3}$ Ontogênese é uma série de transformações sofridas por um ser desde a sua geração até o completo desenvolvimento, ou seja, a evolução individual.

${ }^{4}$ Os exemplos foram copiados exatamente como digitados por seus autores.

${ }^{5}$ Encontrado na comunidade Lev Vygotsky do Orkut, no tópico do fórum Ideologia. Disponível

em: http://www.orkut.com.br/Main\#CommMsgs.aspx?cmm=745511\&tid=8309635\&kw=id eologia. Mesmo que o Orkut seja usualmente considerado uma comunidade virtual sem fins relacionados à aprendizagem, a profundidade das discussões em alguns de seus fóruns pode levar seus integrantes a amplas reflexões sobre o conteúdo abordado, apresentando assim o caráter de CVA.

${ }^{6}$ Ferramentas síncronas são recursos para comunicação em tempo real, tais como chats e programas de comunicação instantânea (Msn, Icq).

${ }^{7}$ Esta funcionalidade faz parte do ambiente virtual de aprendizagem Teleduc.

${ }^{8}$ PASSERINO, Liliana et. al. Mediação por meio de evidências no contexto lingüístico em ambientes virtuais de aprendizagem. SBIE 2008 (no prelo).

\section{Referências Bibliográficas}

BARBOSA, Ana Cristina Lima Santos; PESSOA, Afonso Carlos. Dinâmicas colaborativas no ensino on line: o estado da arte. In: 13 $^{\circ}$ CONGRESSO INTERNACIONAL DE EDUCAÇÃO A DISTÂNCIA, 2007, Curitiba. Anais do $1^{\circ}$ CIED, 2007.2 Disponível em:. http://www.abed.org.br/congresso2007/tc/7302007113323AM.pdf. Acesso em: 29 out. 2008. 
BARROSO, Terezinha. Uma abordagem sociocognitiva e sociodiscursiva da evidencialidade na construção de argumentos em textos de opinião de crianças. Anais do 40. In: SIMPÓSIO INTERNACIONAL DE ESTUDOS DE GÊNEROS TEXTUAIS, v. 4, p. 1905-1917, 2007. Disponível em: http://www3.unisul.br/paginas/ensino/pos/linguagem/cd/Port/128.pdf. Acesso em: 13 junho 2008.

BRANTS, Giovanna Wrubel. Relevância dos processos discursivos na constituição do desenvolvimento cogntivo na primeira infância. Revista Eletrônica de Divulgação Científica em Língua Portuguesa, Lingüística e Literatura. № 08 - jan.junho 2008 . Disponível em: <http://www.letramagna.com/primeirainfancia.pdf>. Acesso em: 13 junho 2008.

CARVALHO, C (2001): Interacção entre pares: Contributos para a promoção do desenvolvimento lógico e do desempenho estatístico no $7^{\circ}$ ano de escolaridade. Departamento de Educação da Faculdade de Ciências, Universidade de Lisboa, Portugal. Tese. 2001. Disponível em: http://cie.fc.ul.pt/membros/ccarvalho/tesecc.pdf. Acesso em: 23 junho 2008.

DA COSTA, Luciano Andreatta Carvalho; FRANCO, Sérgio Roberto Kieling. Aprendizagem Colaborativa na educação a distância: aspectos teóricos, estratégias pedagógicas e experiências realizadas. RENOTE - Revista Novas Tecnológicas na Educação, Porto Alegre, v.4, n.2, dezembro de 2006

MOSCOVICI, Fela. Equipes dão certo: a multiplicação do talento humano. 2.ed. Rio de Janeiro: José Olympio, 1995.

OLIVEIRA, Marta Kohl de. Vygotsky - aprendizado e desenvolvimento um processo sócio-histórico. São Paulo: Scipione, 1995.

PASSERINO, Liliana M.; SANTAROSA, Lucila M. C. Uma visão Sócio-Histórica da Interação Dentro de Ambientes Computacionais. In. V CONGRESSO IBEROAMERICANO DE INFORMÁTICA NA EDUCAÇÃO, Vina del Mar, Chile, 2000. Disponível em: http://lsm.dei.uc.pt/ribie/docfiles/txt200372911757Uma\%20vis\%C3\%A3o\%20s\%C3\% B3cio-hist\%C3\%B3rica.pdf. Acesso em: 19 junho 2008.

PASSERINO, Liliana. Pessoas com autismo em ambientes digitais de aprendizagem: estudo dos processos de interação social e mediação. Programa de PósGraduação em Informática na Educação, Universidade Federal do Rio Grande do Sul, Brasil. Tese. 2005.

PRIMO, Alex. Interação mediada por computador: comunicação, cibercultura e cognição. Porto Alegre: Sulina, 2007.

PRIMO, Alex. Conflito e cooperação em interações mediadas por computador. Contemporanea: Revista de Comunicação e Cultura, v. 3, n. 1, p. 38-74, Jun. 2005. Disponível em: http://www6.ufrgs.br/limc/PDFs/conflito.pdf. Acesso em: 23 junho 2008. 
PRIMO, Alex. Interação mediada pelo computador: a comunicação e a educação a distância segundo uma perspectiva sistêmico-relacional. Programa de Pós-Graduação em Informática na Educação, Universidade Federal do Rio Grande do Sul, Brasil. Tese. 2003.

SARTORI, Ademilde Silveira; ROESLER, Jucimara. Comunidades Virtuais de Aprendizagem: espaços de desenvolvimento de sociabilidades, comunicação e cultura. In: II SIMPÓSIO E-AGOR@, PROFESSOR? PARA ONDE VAMOS? COMFILPUC-SP/COGEAE2003. Nov. 2003. Disponível em: <http://www.pucsp.br/tead/n1a/artigos\%20pdf/artigo1.pdf>. Acesso em: 15 julho 2008.

TOMASELLO, Michael. Origens Culturais da Aquisição do Conhecimento Humano. São Paulo: Martins Fonte, 2003.

VYGOTSKY, L. S.. A Formação Social da Mente. São Paulo: Martins Fonte, 1994.

VYGOTSKY, L. S.. Pensamento e Linguagem. Rio de Janeiro: Martins Fontes, 1998.

ZANK, Cláudia; TIELLET, Cláudio A. B.; CUNHA, Cláudio R.; LONGHI, Magalí T.; SCHMITT, Marcelo A. R.; BEHAR, Patricia A.. Construção de textos coletivos: experiências através de um Groupware. In: V CONGRESSO BRASILEIRO DE EDUCAÇÃO SUPERIOR A DISTÂNCIA (ESUD) e $6^{\circ}$ SEMINÁRIO NACIONAL DE EDUCAÇÃO A DISTÂNCIA (SENAED) - V ESUD e 6 SENAEAD, 2008, Gramado. São Paulo: ABED, 2008. 